February - 2008

\title{
New Ways of Mediating Learning: Investigating the implications of adopting open educational resources for tertiary education at an institution in the United Kingdom as compared to one in South Africa
}

\author{
Tina Wilson \\ The Open University, United Kingdom
}

\begin{abstract}
Access to education is not freely available to all. Open Educational Resources (OERs) have the potential to change the playing field in terms of an individual's right to education. The Open University in the United Kingdom was founded almost forty years ago on the principle of 'open' access with no entry requirements necessary. The University develops innovative high quality multiple media distance-learning courses. In a new venture called OpenLearn, The Open University is making its course materials freely available worldwide on the Web as OERs ( see http://www.open.ac.uk/openlearn). How might other institutions make use of these distancelearning materials? The paper starts by discussing the different contexts wherein two institutions operate and the inequalities that exist between them. One institution is a university based in South Africa and the other is a college located in the United Kingdom. Both institutions, however, deliver distance-learning courses. The second part of the paper discusses preliminary findings when OERs are considered for tertiary education at these two institutions. The findings emphasise some of the opportunities and challenges that exist if these two institutions adopt OERs.
\end{abstract}

Keywords: open educational resources; distance-learning; open education

\section{Introduction}

Every individual worldwide should have access to the widest possible range of educational opportunities. Inequalities of admission to education, however, still exist (Smith \& Casserly, 2006; Brennan, 2004; Bekhradnia, 2004; Badat, 2004; Open Content Initiative, 2006). This inequity manifests itself at an individual country level in the form of differences between the facilities and academic resources provided by various institutions. Comparison of one country with another in terms of provision and fairness of access to education indicates even more inequality (Smith \& Casserly, 2006). In reality, right of entry to education is much more likely in prosperous countries than poor countries (Tomasevski, 2006). Online educational resources are obtainable through Information and Communication Technologies (ICTs). The availability and reliability of ICTs, however, can also be unequal between different countries. Therefore, the 
New Ways of Mediating Learning

Investigating the implications of adopting open educational resources for tertiary education at an institution in the United

Kingdom as compared to one in South Africa

Wilson

straightforward adoption of Open Educational Resources (OERs) cannot be taken for granted. Such issues of unequal access are discussed below in terms of two institutions, one in South Africa and the other in the United Kingdom.

Open Educational Resources (OERs) are shareable assets. The origin and development of OERs is discussed in detail by a number of authors (Smith \& Casserly, 2006; Hylen, 2006; Downes, 2006; Geser, 2007; Wiley, 2006; Wiley, 2007). OERs can play a part in advancing the lifelong learning and social inclusion agendas (Geser, 2007). They have the potential to provide a wide variety of learning experiences for learners in different countries. They provide the possibility of increasing the range and type of learning opportunities available for those who are

- From non-traditional educational backgrounds

- Travelling extensively

- In employment

- And from under represented groups such as:

- The vulnerable

- Those with disabilities

- The house bound

- Those with family dependents

- Those on low incomes or with no income

- Those from low socio-economic groups

- Those seeking refuge from another country

- The elderly

- Those from minority ethnic groups

- Those in prison

Indeed, Smith and Casserly (2006) discuss their vision of OERs contributing to the United Nations Millennium goal of basic education for all by 2015. This paper focuses particularly on the course materials category of OERs.

The idea of sharing content is not new. The Massachusetts Institute of Technology's (MIT) course materials have been available to the world through its Open CourseWare (OCW) initiative since September 2002. Other institutions have followed this lead (e.g., John Hopkins Bloomberg School of Public Health, Rice University Connexions, Utah State University, Sharing of Free Intellectual Assets, Open Learning Initiative from Carnegie Mellon, China Open Resources for Education Initiative and Japanese OCW Alliance, among others). The Open University in the United Kingdom, a well-known and respected distance-learning institution, has joined the OER arena. 
New Ways of Mediating Learning:

Investigating the implications of adopting open educational resources for tertiary education at an institution in the United

Kingdom as compared to one in South Africa

Wilson

The Open University has maintained excellence in the open and distance-learning field for almost forty years. It has been developing and delivering innovative course materials that have undergone a long process of peer review. The University has a strong student base throughout the United Kingdom and is currently increasing its student numbers in other parts of the world. In a new venture called OpenLearn, The Open University is making its course materials freely available worldwide on the Web as OERs. The distinction with The Open University's contribution is that the materials are from supported open and distance-learning courses (McAndrew, 2006). Prior to OpenLearn, the majority of OERs were developed at campus-based institutions where learning and teaching often relies heavily on the lecturer(s)' input to the course materials. The Open University distance-learning materials, by contrast, already embody the lecturer(s) in the form of 'Supported Open Learning.' The high quality Open University materials include many activities (i.e, self assessment and review questions) and, to a large degree, the materials are designed to be self-supporting. In addition, the Moodle enhanced environment supporting OpenLearn provides freely available online forums, unit reviews, unit rating, and community building tools - all of which are advocated by Smith and Casserly (2006).

How might these distance-learning OERs be utilised in different countries worldwide? And what barriers might there be to adoption in developing countries? The work reported here focuses on two institutions that deliver distance-learning courses and the circumstances in which they operate. One institution is a university based in South Africa, and the other is a college in the United Kingdom. This research was undertaken at an early point in the project.

\section{OpenLearn}

OpenLearn is funded by the William and Flora Hewlett Foundation and was launched on October 25 , 2006. The project is adapting distance-learning materials for delivery as multimedia OERs in a Moodle enhanced environment on the Web. These materials are taken from the original Supported Open Learning version of a course (which includes tutorial support and assessment). In the OpenLearn context, the materials called 'units' will be designed to be 'stand alone' - i.e., without tutorial support or assessment.

OpenLearn consists of twin sites, the LearningSpace aimed at learners and the LabSpace aimed mainly at educators (see Figure 1). At launch, 900 study hours of material were made available in the LearningSpace. The number of units and thus study hours in each site will continue to be updated (to make 5,400 learning hours available in the LearningSpace, and 8,100 hours available within the LabSpace by April 2008). The LabSpace is a more experimental area where educators can download units of material, rework them and re-upload them (McAndrew \& Hirst, 2007). 
New Ways of Mediating Learning:

Investigating the implications of adopting open educational resources for tertiary education at an institution in the United Kingdom as compared to one in South Africa

Wilson

Figure 1. The OpenLearn website showing linked captions to the LearningSpace and LabSpace areas

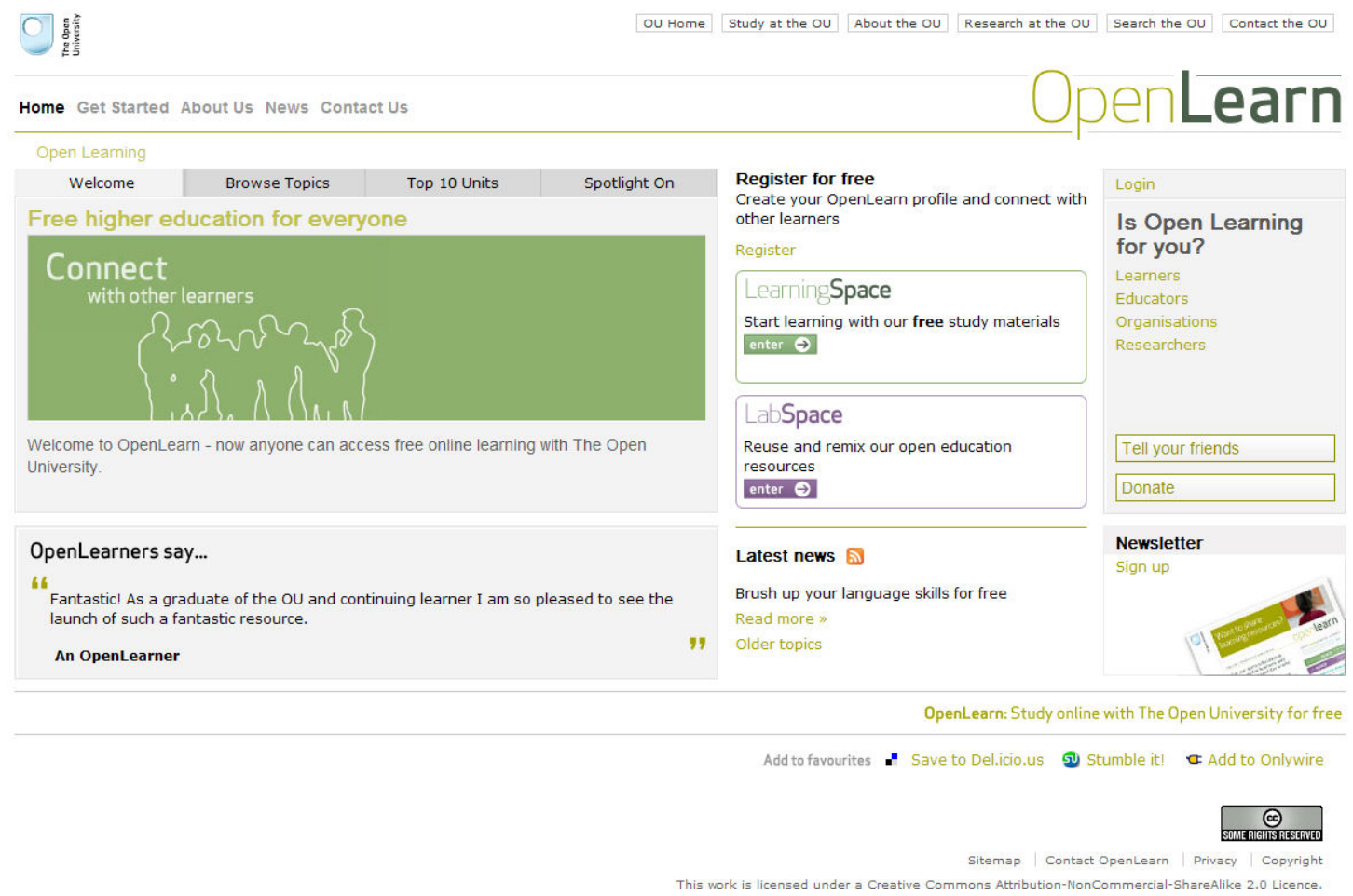

This environment includes units of high quality accessible learning material. These are accessed by clicking on the 'Browse Topics' tab located near the top of the screen (see Figure 1) or by entering the LearningSpace or LabSpace. Each unit of material provides between 4 and 30 hours of study time and is specified at a particular level of study (Lane, 2006). Units contain a variety of multimedia components (see Wilson, 2007).

The learner can interact with the material in the eleven different topic areas. A 'learner' is considered to be anyone and everyone. OpenLearn provides a vast resource, which could support different types of learning and provide valuable insights for a diverse range of students. Individuals or collections of people can choose to work together in organised or amorphous groupings without being constrained by an organisations' timetable, policies, or procedures. On the other hand, a distance-learning institution may choose to use units of OpenLearn OERs as part of their curriculum and decide to give credits or not for the study of this material.

This paper highlights very different circumstances in terms of access to education in South Africa and the United Kingdom. Two distance-learning institutions (one from each of these countries) enable initial research to be undertaken into their proposals for adopting distance-learning OERs that are designed to enhance the teaching and learning experience for learners. 


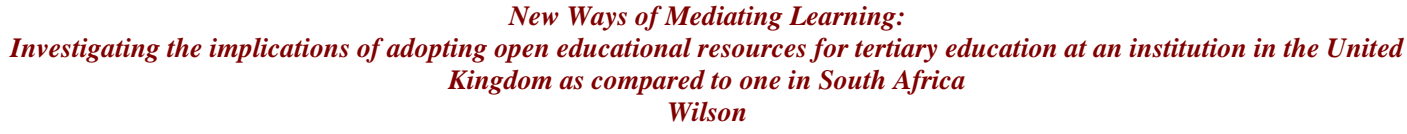

\section{Associated Issues}

First, it is important to outline the various issues that are associated with the development and usage of OERs. Although OERs have great potential to equalise access to educational materials they are not always straightforward to produce. There are issues in setting up repositories to store OERs. The initial set-up, continued support, storage, and updating of content for an open educational resource repository are expensive (Smith \& Casserly, 2006). Ferreira and Heap (2006) discuss the development of OpenLearn OERs and the various roles within this process, including academics who must consider pedagogic and subject issues; rights specialists, who must consider third party issues, and the technical team, whose members must assess whether assets are suitable for online delivery. Sustainability, copyright, intellectual property, and unequal access are all raised as issues with OERs (Smith \& Casserly, 2006; Wiley, 2007; Downes, 2006).

The term OER itself covers a wide range of different types of asset. Textual OERs, however, are the most widely available shareable asset in OER repositories (Wiley, 2007). Mathematical and scientific notation are difficult to display within text, so PDFs are often used (Wiley, 2007). Within OpenLearn, mathematical and scientific notations are displayed as images though these are not resizable.

Certain distance-learning OERs can be developed without any major transformation being necessary. Other resources, however, need to be converted in some manner for use as OERs:

- The resource may be taken out of context and needs to be changed so that it can standalone.

- The original material may need to be presented in a different way to suit online delivery (e.g., long audio, video sequences, and software).

To ensure compatibility between repositories, OERs should be developed in such a way that they are easily reusable: technically, linguistically, culturally, and pedagogically (Wiley, 2007). Wiley, in discussing OERs delivered mainly by campus-based institutions, suggests that it is expensive to develop OERs from scratch or from the different components a lecturer might use in their course delivery at a campus-based institution. Essentially, what Wiley is saying is that it is more expensive to develop OERs for student usage than for educators. This argument is less relevant to the Open University OERs, however, as the material was originally developed to be stand alone, primarily for student consumption. This suggests that conceivably more distance-learning materials (which already embody the lecturer in the form of 'Supported Open Learning') should be transformed into OERs, because potentially they are less expensive to produce as stand alone materials. Issues associated with the actual transformation of Open University distance-learning course materials into OERs is discussed in greater detail by Wilson (2007).

\section{Approach}

This early stage research sets out to explore the ease or difficulty with which distance-learning OERs can be adopted by two distance-learning institutions operating in different circumstances. Data was collected to give early indications and feedback for the project, and to provide data that could be compared with other findings at a later date. Follow-up research will analyse what the 
issues are more widely, and include traditional campus-based institutions that wish to adopt these distance-learning OERs. The data was gathered at an early stage (less than four months after the OpenLearn environment was launched) to gather initial information from potential users. The work discussed here is part of a larger project involving 12 representatives from 11 institutions worldwide.

The two institutions discussed in this paper were identified as appropriate as they were both aware of the work of The Open University and deemed to be in a position to re-use distancelearning OERs. One institution, a university, is based in South Africa and the other, a college, is situated in the United Kingdom (the participants and their institutions are discussed further below). Both institutions are involved in distance-learning provision. By comparing an institution in the United Kingdom with one in South Africa, the conditions and implications for an institution in a developing country can be compared with those of a developed country.

In terms of data gathering in these institutions, OECD CERI (2007) reported poor results from a survey aimed at high-ranking members of organisations, thereby suggesting that OER development was perhaps a grass roots process. For that reason, a decision was made to contact senior members of institutions and conduct in-depth interviews rather than conduct a wider survey of staff opinion as, indeed, requests for return of survey questionnaires can more easily be ignored than can requests for interviews.

The South African university involved in this study has been delivering a number of distancelearning courses through study centres since 1996. This university allocates funds to make education more accessible to those from disadvantaged groups. The interviewee is a professor who represents a faculty within the university. The professor consulted 21 lecturers responsible for distance education programmes at the South African university, and provided a summary of their responses in the interview. The professor was selected, as it was determined that $\mathrm{s} / \mathrm{he}$ was in a position to provide a 'good overview' from a faculty perspective.

The distance-learning college, located in the United Kingdom, involved in this study has been delivering a number of distance-learning courses for more than forty years. In the main, this college's students are adults and study from home. Widening of participation of adults in education is at the heart of this college's undertaking. The courses available are either preuniversity courses or lead to professional qualifications. The interviewee is a director of the college, and was selected because it was determined that s/he represented the 'high level views' of the whole college.

To understand the implications for distance-learning institutions adopting OERs the following questions were asked:

- Which topic areas within OpenLearn would be of interest to learners?

- Would OpenLearn material fit within the present curriculum?

- Would OpenLearn material fit within the timetable of study?

- What expectations do the institutions have of using OERs with learners? 
New Ways of Mediating Learning:

Investigating the implications of adopting open educational resources for tertiary education at an institution in the United

Kingdom as compared to one in South Africa

Wilson

- Would the institutions provide assessment for the OpenLearn material?

- What form would assessment take?

- What implications are there in terms of policies and procedures when using OER's for accreditation?

- Would OpenLearn material be better suited to learning in cases of non-accreditation?

These questions were designed to address the issues of usage, unequal access, assessment, accreditation and non-accreditation, as discussed by Smith and Casserly (2006). Although many OERs have been made available worldwide, little is known in terms of quality research about who is actually using OERs (Hylen, 2006; Wiley, 2006).

The interview with the participant in the South African university took place between February 15 and February 20, 2007; the interview with the college in the United Kingdom took place between January 17 and February 5, 2007. Interviews were used to gather detailed information (Zand, 1994), and were semi-structured (Preece, Rogers, Sharp, Benyon, Holland \& Carey, 1994; Zand, 1994; Fowler,1993). As the interviewer and interviewee were located long distances apart, the exchanges with each institution took place as a personal online semi-structured interview, termed as an epistolary interview (Debenham, 2001). The semi-structured interview schedule was piloted in advance with two researchers. This paper discusses nine questions asked in the personal online semi-structured interviews. Seven of these questions were of an open type, requiring 'open-ended' responses. Two questions were of a 'closed ended' type. In response to queries and to help overcome misunderstandings, sub-questions and additional background information was supplied online. As such, ongoing conversations developed overtime.

The data from the interviews is comprised of the users' opinions as expressed in mainly open responses in the personal online semi-structured interviews. The interview transcriptions were broken down into separate responses. The 'open-ended' responses from both interviewees were compared, so that interesting suggestions could be identified.

\section{The Unequal Context in Which the Two Institutions Operate}

As indicated in the Introduction, the unproblematic adoption of OERs worldwide cannot be assumed, and thus consideration needs to be given to the underlying circumstances and political climate that prevails in different countries. As Tomaseveki (2006) noted: "Education should be free and compulsory . . ." but ". . . what is mandated by international human rights law reflect deep divisions within the international community. . . The resistance to defining education as a human right informs global education strategies” (pp. pxvii to xix and xxiii). There is conflict between an individual's rights and governments' promises (Tomasevski, 2006).

The two institutions involved in this research are delivering distance-learning courses in different circumstances. They are:

- Based in different countries

- Using different infrastructures to access ICTs 
- Working within different educational policies, and

- Teaching at different levels

Such variety of circumstances begs for an initial investigation into the opportunities and challenges that can arise.

Although access to OpenLearn itself would not involve a cost to learners, what method of access would learners use and how much might that access cost? To analyse the extent to which access is either equal or unequal, let us now look at the situation in each country wherein each institution is based.

\section{South Africa: Educational policy and access to ICTs}

Though South Africa's higher education system can boast of many merits, equality of access to education has not always been one of them. The end of apartheid in the early 1990s provided a major opportunity for change (Badat, 2004; Brennan, King, \& Lebeau, 2004). As Badat (2004) wrote, "One key policy imperative of democratic South Africa is to transform higher education so that it becomes more socially equitable ...” (p. 2). According to this author, equal opportunity together with improved research, teaching, and learning strategies would enable South Africa to participate more fully in the global economy.

Tomasevski (2006), however, argues that education in South Africa has not played its part in the transition from apartheid. She reports that South Africa does not have legal guarantees of free primary education.

According to Tomasevski (2006), "The post-apartheid government [of South Africa] has not managed to universalise education or to make it free after a full decade of having in place a constitutional guarantee of basic education for all” (p. 58). There are plans to have both 'fee-free' and 'for-fee' schools, which Tomasevski argues will only increase inequality in education, as the 'for-fee' schools will provide a much better learning experience than the 'fee-free' schools. She also reports that 11 percent of South African school age children do not even register to attend school.

In addition, there are inequalities of access to fixed telephone lines, modern computers, and the Internet in Sub-Saharan Africa (Ivala, Siluma-Mmekoa, \& Butcher, 2005; Spronk, 2001; Smith \& Casserly, 2006). Internet access is not widely available and tends to be situated in large cities rather than rural areas (Ivala et al., 2005; Atkins, Seely Brown, \& Hammond 2007). Less than 10 percent of the population has access to the Internet; nonetheless, this still puts South Africa ahead of Kenya, Nigeria, and Tanzania (Ivala et al., 2005).

Ivala and colleagues (2005) estimate that more than 50 percent of students and staff in higher education in South Africa are Internet users and that higher education institutions are spending more on improving such facilities. This figure, however, appears not to be true for all universities. Indeed, Connolly, Wilson and Wolfenden (2007) reported that only two percent of the students had access to the Internet on the distance teacher education programmes at the University of Pretoria. Atkins and colleagues (2007) further concur that ability to access the Internet in Africa is between two and five percent. In addition, high-speed Internet access remains very expensive 
New Ways of Mediating Learning:
Investigating the implications of adopting open educational resources for tertiary education at an institution in the United Kingdom as compared to one in South Africa

Wilson

for African universities compared to costs of high-speed access borne by similar institutions in the developed world.

Roelen, Rienties and Tempelaar (2007), who were concerned with bandwidth capacity and capabilities in Africa and Asia, nonetheless found that students (from developing countries) who studied a higher education course online reported learning online as a positive experience. These students were based in Africa and Asia, and studied with a tutor based in Maastricht. Roelen and colleagues also found that accessing the online facilities did not prove to be difficult, as students reported that they could either use the facilities of their employer (the ministry) or use Internet cafés. The availability of these facilities, however, suggests though that these students were located in urban or city areas rather than rural areas.

One ray of hope is that the widening availability of mobile phones in rural Sub-Saharan Africa and the increased provision of Internet access will facilitate the adoption of OERs in rural areas. The largest increase in mobile phone networks between 2000 and 2005 in the world can be seen in Sub-Saharan Africa (Atkins et al., 2007). Indeed, Atkins and colleagues (2007) propose that the mobile phone or hand held devices will become a popular method used by most people to access the Internet. Ivala and colleagues (2005), however, reported that mobile phones have not yet been used to access the Internet in the African Continent.

In terms of policy, Brennan and colleagues (2004) found that, "Nearly all universities had been under pressure to reform curricula and to introduce new forms of academic recognition and quality assurance” (p. 8). A White Paper examining e-Education was released by the Department of Education in South Africa in 2004 (Ivala et al., 2005). A key feature of this White Paper is an assertion that all those working and learning in an educational institution should be self-assured and inspired enough in their use of ICT to develop their skills and knowledge for lifelong learning (Department of Education, 2004). Also, countries in Sub-Saharan Africa have been in deep contemplation about how ICTs could be used in educational contexts from school level right through to university (Swarts, 2007).

\section{United Kingdom: Educational policy and access to ICTs}

Although the United Kingdom is a developed country within Western Europe, inequalities of access to education do and still exist. Different institutions have differing entry requirements. Their resources, particularly in terms of staff and equipment, vary considerably and hence they provide dissimilar learning experiences for their students. Although children are encouraged to stay on at school after the age of 16, they must satisfy entry requirements and be in a position to pay tuition fees; as a consequence, students from low socio-economic and minority ethnic groups only comprise a small proportion of the British student population.

Access to ICT facilities is much more prevalent in Western Europe than in developing countries so much that institutions of all descriptions are adopting online learning environments to enhance teaching and learning processes, and moving towards e-learning approaches for course delivery. An integral part of this e-learning agenda is the inclusion of a Virtual Learning Environment (VLE) such as WebCT, BlackBoard, or Moodle. These VLEs host course materials and communication facilities, although access typically is password protected. Access to online facilities in the United Kingdom, however, can be prohibitively expensive, especially to those on low incomes or with no income at all. 
New Ways of Mediating Learning:

Investigating the implications of adopting open educational resources for tertiary education at an institution in the United

Kingdom as compared to one in South Africa

Wilson

Student numbers have been increasing at institutions in the United Kingdom. Indeed, directed by British Government to increase student numbers, but without additional funding, institutions have recruited many more students than necessary, meaning that they grew more quickly in size than was perhaps prudent (Bekhradnia, 2004).

The 2003 White paper indicates that the British Government expects nearly 50 percent of 18 to 30 year olds to participate in some form of higher education. Bekhradnia (2004), however, argues that it will take more than government policy to truly widen access to education. He suggests that higher levels of achievement in different social groupings while at school will influence a more diverse range of students to apply to institutions.

\section{Availability and Accessibility of High Quality Material}

How will the differences between the United Kingdom and South African contexts described here affect the ability of the two institutions in question to adopt OERs? The interviewees at the two institutions involved in this research were asked if they were aware of the OpenLearn website, and how they had come to know about it. Both interviewees reported that they were aware of the website. The interviewee at the university in South Africa mentioned that they had heard about OpenLearn by word-of-mouth and through links on the Internet. The interviewee located at the college in the United Kingdom became aware of OpenLearn through participation in a local workshop.

The subsequent question involved the OpenLearn topic areas that are of interest to the two interviewees and their institutions. As mentioned above, there are 11 different topic areas within OpenLearn:

- Arts and History

- Business and Management

- Education

- Health and Lifestyle

- IT and Computing

- Mathematics and Statistics

- Modern Languages

- Science and Nature

- Society

- Study Skills

- Technology 
Each topic area comprises a variety of units, with different study-hour and level allocations as indicated earlier. The interviewees were asked about which topic areas within OpenLearn they felt would be of interest to their learners. It is perhaps surprising to find that both institutions (though based in different countries and teaching at different educational levels) chose very similar topics. The university in South Africa chose 10 of the 11 topics (leaving out ICT and Computing) while the college in the United Kingdom chose nine of the 11 topics (leaving out Technology, ICT and Computing). This suggests that the OpenLearn topics could provide a large pool of useful OER units for both of these distance-learning institutions.

\section{Opportunities and Challenges Adopting OERs}

A wide variety of topic areas clearly appeared to be of interest to both institutions, although it was also important to establish the extent to which the OpenLearn material would actually fit within each institutions' present curriculum offering. The university in South Africa responded that the OpenLearn OERs would fit well within their present curriculum, but implied that they would not accommodate all their learners' requirements. This interviewee also consulted the lecturers responsible for distance education programmes at the university in South Africa. The summary of the lecturers' responses was as follows:

- The "majority of lecturers [were] in favour especially for additional reading."

- "Some material might fit in with our programmes, but others are not even covered as far as we know”.

These responses suggest that the OpenLearn units would fit in with the curriculum as a form of supplementary material, and that OpenLearn provides units in areas that are not yet covered by the university in South Africa.

By contrast, the college in the United Kingdom indicated that the OpenLearn units would not fit directly with their curriculum, but “. . . could provide some optional added interest”. This suggests that the OpenLearn material would be complementary to current curriculum offerings. As the materials on OpenLearn are mostly at university level, perhaps they are not directly relevant to a college.

Another issue was whether the OpenLearn material would fit within the two institutions timetable of study. The university in South Africa indicated that the OpenLearn units of material would not fit into their present timetable of study. The interviewee, however, clarified this statement further by saying "we will first have to look at your material and see how we can adapt it to our situation" and consider the "time allocation" to do this. It is not surprising, however, that time would be required to reflect on the present curriculum and how these new materials could become integral to the university's offerings. A number of other issues come into play here also. The OpenLearn materials in the main are written in English, although some have been translated into other languages. Moreover, the materials are designed for a mainly Western European audience. 
New Ways of Mediating Learning:

Investigating the implications of adopting open educational resources for tertiary education at an institution in the United

Kingdom as compared to one in South Africa

Wilson

In adapting the OpenLearn materials, the South African university would also have to consider the issue of language because:

- English is not the first language for most African people (Ivala et al., 2005).

and

- the need to localise content for the audience (Connolly et al., 2007).

Cultural and linguistic issues concerning the adoption of OERs are also discussed by Wiley (2007).

The college in the United Kingdom was unsure about whether the material would fit into their timetable of study, as their "students don't work in cohorts" and they tend to work individually and at their own pace. An option for the college might be to consider their tutors as a guide to point students to relevant units within OpenLearn.

The interviewees were then asked about their institutions' expectations of how they will use OERs with their learners. The interviewee in the university in South Africa again consulted the lecturers responsible for distance education programmes at the university. The following responses were received:

- “Downloading from Internet”

- "Expose students on an experimental basis to this type of learning”

- "Personal and professional development of students can be promoted"

- "To connect your subject content to some of our modules"

- "Can be used as additional sources"

These responses suggest that the OpenLearn units can be used to change the teaching practice in the university in South Africa, a favourable outcome as advocated by Geser (2007). First, this outcome would be achieved by promoting different types of learning, and second by linking to subject specific content, and finally by adopting supplementary material. The college in the United Kingdom suggested the viability of linking to specific relevant units within OpenLearn. "We could provide selections of links to appropriate topics from the student interest groups for each course.” Both of these institutions envisioned ways that they could adopt OERs for use with their students.

It seems clear that the OpenLearn units will be a valuable resource for both of these institutions. Would these institutions, however, provide assessment for the OpenLearn material? And if yes, what form would this take? The South African university confirmed that they would assess the OpenLearn content once they "are aware of the type of content." They would assess it as "part of an assignments, as well as part of a portfolio where applicable. By means of a trial run: include some material in a section of our programme and letting students give feedback.” The college in the United Kingdom, for instance, reported that it is "very unlikely [that we would assess use of 
New Ways of Mediating Learning:

Investigating the implications of adopting open educational resources for tertiary education at an institution in the United

Kingdom as compared to one in South Africa

Wilson

the Open Learn units] initially.” However, "if we were subsequently to provide assessment - then it could be, perhaps, in a relatively open-ended assignment, asking learners to select material for themselves and work with it and report, back to the tutor ... or in the form of short accompanying quizzes”.

The next issues addressed were those of policy and procedure that would need to be used or changed to allow the adoption of OpenLearn units for assessment. The university in South Africa reported that assessment of OpenLearn units would "have to be discussed with the director of our faculty, as well as with the director of the School. . . We must also be aware of the policies and procedures at Open Learn.” It is not surprising that this is a difficult question to answer, especially given that the university in South Africa has not had time to consider, in detail, how they would adopt OpenLearn OERs. It will be interesting to revisit this issue with the South African university in the future. The college in the United Kingdom, on the other hand, was able to give a definite response. "For formal assessment - we are tied to the requirements of awarding bodies. As a rule, students are interested in studying only what relates directly to the award. So we'd be unlikely to use your material for this.” It appears, therefore that the college in the United Kingdom would use a more informal assessment for OpenLearn material.

The interviewees were then asked whether they felt OpenLearn material would be better suited to learning in cases of non-accreditation. The interviewee at the university in South Africa was unable to say whether or not the OpenLearn OERs were more suited for circumstances of nonaccreditation, indicating that "This material will have to be tested in some way with our students' in a pilot form at first.” The interviewee at the college in the United Kingdom response was much more in favour of the OERs being used in circumstance of non-accreditation. According to this interviewee, "they could be used 'for informal assessment - for example, in a quiz, or in an analysis, in our learning skills courses. No issues of policy or procedural change here, but the wider OpenLearn option (and links to the site as a whole) would have to be just that, since not all our students have online access.”

OpenLearn units therefore may be used in the future for either accreditation or non-accreditation. An interesting issue, which could affect the accessibility of the OERs and thus any such assessment of them, is whether all distance-learners have access to the Internet. As pointed out earlier, those living in rural areas of Africa may not have a reliable electricity supply, and the college in the United Kingdom has indicated that some of their students are unable to access the Internet.

\section{Limitations and Conclusions}

This early stage research was undertaken less than four months after the OpenLearn environment was launched and has certain inherent limitations. The two interviewees actively involved in the study account for a very small proportion of potential users of OERs. This therefore calls for caution in interpreting the findings. They provide only initial data from the distance-learning institutions' perspective on the adoption of distance-learning OERs, which can then be compared with data collected at a later date. Each interviewee can give only limited feedback on the policies of a complex institution. Nonetheless, this early stage study does point to areas that merit further investigation. 
New Ways of Mediating Learning:

Investigating the implications of adopting open educational resources for tertiary education at an institution in the United

Kingdom as compared to one in South Africa

Wilson

This paper started by relating the unequal contexts in which a South African university and a college in the United Kingdom function. The discussion covered access to education, to ICTs, and the influence of government policy. Inequalities in educational achievements between developed and developing countries do exist as a result of vastly different levels of funding. Developing countries strive for primary education for all as a long-term goal, whilst developed countries aim for secondary education for all followed by lifelong learning (Tomasevski, 2006). In the United Kingdom, there is a legal guarantee of free and compulsory education and parents receive a family allowance (Tomasevski, 2006), which can be used to offset any additional costs. We should not, however, forget the situation of the poor living in developed countries (Tomasevski, 2006) and how the cost of tuition fees affects entry to post compulsory education. Though communication facilities offer many opportunities to support learning and teaching over long distances (Krause, 2005; Spronk, 2001) the reality in developing countries can be rather different. Spronk (2001) highlights:

- Poverty

- Political upheaval

- High levels of illiteracy

- Unreliable access to electricity (Atkins et al., 2007; Spronk, 2001)

- Low levels of ownership of telephone lines, radios, televisions, and access to the Internet (Ivala et al., 2005; Spronk, 2001)

One would expect that OERs could not be as easily adopted in a developing country, particularly given limited access to education and ICTs. The interviewee from the university in South Africa involved in this study reported that some of these issues are still relevant in 2007. "Some students in the urban areas do have access to Internet facilities, while students in the deep rural areas might not even have electricity to use computers.” This is further evidence of the inequalities of access to commodities between urban and rural areas in South Africa. The interviewee from the South African university, however, did not highlight any other barriers to the adoption of OERs. Indeed, Atkins and colleagues (2007) are optimistic about improved networking in sub-Saharan Africa, but stress that the supporting technology cannot be taken for granted. The importance of being able to work offline is further emphasised by Esslemont (2007).

OERs alone will not solve all of the problems related to the availability of educational resources. If infrastructure and facilities are not put in place to access the Internet, then access to distancelearning OERs will not be possible. Alternatives types of OER (Connolly et al., 2007; Wiley, 2007) will need to be considered in these cases to improve distribution and access. In the United Kingdom where access to ICTs is more prevalent, OERs should be made more available. For example, through provision in libraries, job centres, prisons, and detention centres.

OERs present a prospect of improving access to education throughout the world. Hylen (2006) argues that the sharing of information, including educational resources, helps to reduce social inequalities. Access to updated computing facilities and the Internet have improved over the last ten years, although reciprocal changes have not occurred in teaching methods to improve graduates' participation in the knowledge economy and society (Geser, 2007). If teaching methods can be changed to truly take advantage of OERs, then more engaging methods of 
teaching may attract all types of learners. Indeed, in this preliminary research the university in South Africa indicated that the adoption of OERs could change the style of teaching at the university. Moreover, there is little difference in the appeal of new technology to the younger generation, whether they are based in developing or developed countries (Atkins et al, 2007). Also, students expect technology to support them with their studies while on the move (Krause, 2005).

In this study, 9 of the 11 OpenLearn topics were of interest to the two interviewees from the institutions involved in this research. This suggests that units within the different topics could provide a large and valuable repository of units for many institutions, groups, and individuals worldwide. This is in line with Vest's (2004) article indicating that the MIT OERs appear to be valuable to other institutions. The OpenLearn materials seem particularly valuable to the programmes of study at the South African university. Since the materials are mainly at higher education level and of a distance-learning type, perhaps this is not surprising; though Heller and Torun (2007) found that OERs are more likely to be used within the context of an educational programme. In any case, accessible OpenLearn material that has undergone extensive peer review to ensure high quality will likely be a valuable resource in both developed or developing countries. The OpenLearn OERs can provide supplementary or complementary resources to institutions. This corresponds with the OECD CERI (2007) study, which found that "instructors view OER as a high-quality complement to other resources." (p. 52). In the case of the South African university, the interviewee indicated that they would see the OERs as fitting in well with their present teaching commitments and curriculum. Interviewees from both institutions indicated that they would link to the OpenLearn units from their own websites. Both interviewees indicated that they would assess their students' use of the OER units given adequate time to assimilate their content. While the interviewee from the university in South Africa indicated that they would use formal assessment, the interviewee from the college in the United Kingdom would favour more informal assessment. The findings from the college in the United Kingdom with respect to using the OER material for non-accreditation concur with the reasoning of Smith and Casserly (2006) and is in line with that of Heller and Torun (2007) who are starting to look at accreditation issues for public health courses in developed and developing countries.

The enthusiasm of the interviewees from these two institutions to use the OpenLearn distancelearning OERs (with the lecturer embedded in the material in the form of 'Supported Open Learning') suggests that more distance-learning OERs should be made available. As mentioned earlier, the cost of transforming distance-learning course material into OERs may be less than that suggested by Wiley (2007) for OERs developed at campus-based institutions.

These findings provide a basis on which to undertake further research. Moreover, it will be interesting to more fully determine how distance-learning OER units are adopted in reality, in both of these institutions and in traditional campus-based institutions.

A higher-level question, which should also be asked is 'how might distance-learning institutions change to promote life long learning?' How will they cater to those who want a mix of courses, some for accreditation and some without accreditation? Indeed, learners' reported their desire to study for their qualifications at a number of different institutions (Krause, 2005), by picking and combining a portfolio of courses and modules by which to earn their qualification. The adoption of OERs could be part of a solution to this current issue. 
New Ways of Mediating Learning:
Investigating the implications of adopting open educational resources for tertiary education at an institution in the United

Kingdom as compared to one in South Africa

Wilson

\section{Acknowledgments}

The author would like to thank the William and Flora Hewlett Foundation who fund and support The Open University, Open Content Initiative: OpenLearn

\section{References}

Atkins, D. Seely Brown, J., \& Hammond, A. (2007). A Review of the Open Educational Resources (OER) Movement: Achievements, challenges, and new opportunities. A Report to The William and Flora Hewlett Foundation. Retrieved May 31, 2007 from: http://www.oerderves.org/wp-content/uploads/2007/03/a-review-of-the-open-educationalresources-oer-movement_final.pdf

Badat, S. (2004). Higher education and society in post-apartheid South Africa. In Ten Years On: Changing higher education in a changing world (pp. 2-6). The Open University: Milton Keynes. Retrieved August 2, 2007 from: http://www.open.ac.uk/cheri/index.htm

Bekhradnia, B. (2004). 20 Years of higher education policy in the United Kingdom: looking back 10 years and forward to the next decade. In Ten Years On: Changing higher education in a changing world (pp. 11-21). The Open University: Milton Keynes. Retrieved August 2, 2007 from: http://www.open.ac.uk/cheri/index.htm

Brennan, J. (2004). The Social Role of the Contemporary University: Contradictions boundaries and change. In Ten Years On: Changing higher education in a changing world (pp. 22-26). The Open University: Milton Keynes. Retrieved August 2, 2007, from: http://www.open.ac.uk/cheri/index.htm

Brennan, J., King, R., \& Lebeau, Y. (2004). The Role of Universities in the Transformation of Societies: An international research project - synthesis report. Association of Commonwealth Universities \& The Centre for Higher Education Research and Information: Milton Keynes. Retrieved August 1, 2007 from: http://www.open.ac.uk/cheri/pdfs/tr final report.pdf

Connolly, T., Wilson, T., \& Wolfenden, F. (2007). Reaching the Boundaries of the Global South: Exploring the importance of guidelines for the localisation of OERs. In proceedings of Open Education 2007: Localizing and learning, September 26-28, Logan, Utah.

Department of Education (2004). White paper on E-Education. Pretoria.

Debenham, M. (2001). Computer Mediated Communication and Disability Support: Addressing barriers to study for undergraduate distance learners with long-term health problems. Doctoral Thesis. Milton Keynes: The Open University.

Downes, S. (2006). Models for sustainable Open Educational Resources. OECD experts' meeting on Open Educational Resources, Malmo Sweden, February 2006. Retrieved January 29, 2008 from: http://www.downes.ca/cgi-bin/page.cgi?post=33401 
New Ways of Mediating Learning:

Investigating the implications of adopting open educational resources for tertiary education at an institution in the United

Kingdom as compared to one in South Africa

Wilson

Esslemont, C. (2007). Bridging the Abyss: Open content to meaningful learning. In Proceedings of OpenLearn 2007: Researching open content in education (pp. 44-46), October 30-31, 2007, Milton Keynes. Retrieved January 29, 2008 from:

http://kn.open.ac.uk/public/getfile.cfm?documentfileid=12174

Ferreira, G., \& Heap, N. (2006) From Print to Web: Issues in re-purposing for an Open Resources Repository. Proceedings of the 2006 EADTU Conference, November, 23-24, 2006, Tallin, Estonia. Retrieved August 20, 2007 from:

http://kn.open.ac.uk/public/document.cfm?docid=8979

Fowler, F. J., Jr. (1993). Survey Research Methods (Second edition) Newbury Park, CA.: Sage Publications.

Geser, G. (Ed.) (2007) Open Educational Practices and Resources, OLCOS Roadmap 2012. Salzburg Austria: Salzburg Research Edumedia Research Group. Retrieved August 24, 2007 from: http://www.olcos.org/cms/upload/docs/olcos roadmap.pdf

Heller, R., F., \& Torun, P. (2007). Embedding Open Content in Education: peoples-uni.org. In Proceedings of OpenLearn 2007: Researching open content in education (pp. 55-57) October, 30-31, Milton Keynes, UK.

Hylen, J. (2006) Open Educational Resources: Opportunities and challenges. Proceedings of Open Education 2006: Community, culture and content. September 27-29, Utah State University (pp. 49-63). Retrieved August 28, 2007 from: http://cosl.usu.edu/conferences/opened2006/docs/opened2006-proceedings.pdf

Ivala, E., Siluma-Mmekoa, E., \& Butcher, N. (2005). Online access and connectivity of primary school teachers in sub-Saharan Africa. Braamfontien: South African Institute for Distance Education (SAIDE). Retrieved August 1, 2007 from: http://www.tessaprogramme.org/pdf/d50716.pdf

Krause, K. (2005). The Changing Face of the First Year: Challenges for policy and practice in research-led universities. Keynote Paper. First Year Experience Workshop 2005: University of Queensland, Brisbane, Australia. Retrieved August 28, 2007 from: http://www.uq.edu.au/teaching-learning/docs/FYEUQKeynote2005.doc

Lane, A. (2006). From Pillar to Post: Exploring the issues involved in re-purposing distance learning materials for use as open educational resources. Retrieved August 30, 2007 from: http://kn.open.ac.uk/public/document.cfm?docid=9724

McAndrew, P. (2006) Motivations for OpenLearn: The Open University's open content initiative. Paper presented at the OECD experts meeting on Open Educational Resources. October 2627, Barcelona. Retrieved August, 28, 2007 from: http://kn.open.ac.uk/public/document.cfm?docid=8816 
New Ways of Mediating Learning:

Investigating the implications of adopting open educational resources for tertiary education at an institution in the United

Kingdom as compared to one in South Africa

Wilson

McAndrew, P., \& Hirst, T. (2007). Open content for open development. The second TenCompetence workshop on Service Oriented Approaches and Lifelong Competence Development Infrastructures. January 11-12, Manchester.

OECD CERI (2007). Giving Knowledge for Free: The emergence of open educational resources. Milton Keynes: The Open University, Centre for Educational Research and Innovation (CERI). Retrieved August 2, 2007 from: http://www.oecd.org/document/41/0,3343,en_2649_201185_38659497_1_1_1_1,00.html

Open Content Initiative (2006). Funding proposal to the William and Flora Hewlett Foundation. Milton Keynes: OpenLearn. Retrieved August 3, 2007 from: http://www.open.ac.uk/openlearn/_assets/06sngpqpwminsmwxov.pdf

OpenLearn (n.d.). The Open University OpenLearn website. Retrieved January 29, 2008 from: http://www.open.ac.uk/openlearn

Preece, J., Rogers, Y., Sharp, H., Benyon, D., Holland, S., \& Carey, T. (1994). Human Computer Interaction. Wokingham, UK.: Addison-Wesley.

Roelen, K, Rienties, B., \& Tempelaar, D. (2007) The use of ICT in higher education to support capacity development in developing countries. In proceedings CAL '07 Development Disruption and Debate. March 26-28, 2007 Dublin, Ireland.

Smith, M. S., \& Casserly, C. M. (2006). The promise of open educational resources. Change 38(5), 8-17.

Spronk, B. (2001). Naming the learning technology issues in developing countries. In E. J. Burge \& M. Haughey (Eds.) Using Learning Technologies: International perspectives on practice. London: RoutledgeFalmer.

Swarts, P. (2007). The African context for ICTs in teaching and learning. In proceedings CAL '07 Development Disruption and Debate. March 26-28, Dublin, Ireland.

Tomasevski, K. (2006). The State of the Right to Education Worldwide. Free of fee: 2006 Global report. Self published report. Copenhagen. Retrieved August 28, 2007 from: http://www.katarinatomasevski.com/images/Global_Report.pdf

Vest, C. M. (2004, January 30). Why MIT decided to give away all its course materials via the Internet. The Chronicle of Higher Education, 50(21), B20. Retrieved August 28, 2007 from: http://web.mit.edu/ocwhq/pres/facpack/ChronHigherEd_1-30-04.pdf

Wiley, D. (2006). Organisation for Economic Co-operation and development. Paper for Expert Meeting on Open Educational Resources, OECD-CERI, February 6-7, Malmö, Sweden. Retrieved July 28, 2007 from: http://www.oecd.org/dataoecd/19/26/36224377.pdf

Wiley, D. (2007). Open Educational Resources: On the Sustainability of OER initiatives in Higher Education. Paper commissioned by the OECD's Centre for Educational Research and Innovation (CERI) for the project on Open Educational Resources. Retrieved July 1, 2007 from: http://www.oecd.org/dataoecd/33/9/38645447.pdf 
New Ways of Mediating Learning:

Investigating the implications of adopting open educational resources for tertiary education at an institution in the United Kingdom as compared to one in South Africa Wilson

Wilson, T. (2007). Transformation for an Open Education Repository: Issues associated with IT and Computing distance learning course materials. In proceedings of the international conference, Information Technologies: Theory, Practice, Innovations (pp. 143-147). December 6-7, 2007, Alytus, Lithuania.

Zand, H. (1994). Developmental Testing: monitoring academic quality and teaching effectiveness'. In Fred Lockwood (Ed.), Materials Production in Open and Distance Learning (pp. 121-130). London: Paul Chapman Publishing.

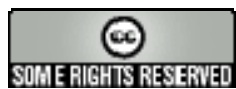

